\title{
Deterministic Application of Process-centric Law to the System-centric Requirements of Procurement Procedures
}

\section{P.E.R}

Pioneer in peer-reviewed, open access online law publications

Author

David Wickens

Affiliation

Independent technology procurement consultant South Africa

Email

dave@wickens.co.za

Date Submission

11 March 2018

Date Revised

14 May 2021

Date Accepted

14 May 2021

Date published

28 May 2021

\section{Editor Prof C Rautenbach}

How to cite this article

Wickens D "Deterministic

Application of Process-centric Law to the System-centric

Requirements of Procurement

Procedures" PER / PELJ 2021(24)

- DOI

http://dx.doi.org/10.17159/1727-

3781/2021/v24i0a4549

Copyright

http://dx.doi.org/10.17159/1727-

3781/2021/v24i0a4549
DO

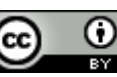

\section{Abstract}

South Africa's public procurement system is accorded constitutional status, establishing fundamental requirements for the operation of the system. The application of these constitutional system requirements and their interpretation in the judicial adjudication of procurement cases have highlighted the tension between the administrative, or process-centric, legal requirements and the system-centric nature of procurement procedures. The importance of a deterministic approach for procurement decision-making can be considered from two angles - the certainty of the procurer in the conformity of its own conduct and external certainty to diminish the risk of unnecessary challenge.

This article revisits the foundational rationale for system-based procurement procedures and associated decision-making for its potential for finding a deterministic approach to balancing the legal requirements, both system- and process-based. These principles are tested against a selection of adjudicated outcomes to formulate practical recommendations for practitioners aimed at deterministic decision-making in the procurement process.

\section{Keywords}

Public procurement regulation; disqualification; tenders; auction; procurement system; constitutional procurement; exclusion; decision theory. 


\section{Introduction}

A feature of South Africa's public procurement regime is the constitutional status accorded to its underlying principles. Section 217 of the Constitution of the Republic of South Africa, $1996^{1}$ establishes fundamental requirements for the system according to which an organ of state must contract entrenching the legitimacy of preferential and other measures aimed at achieving substantive equality in such a system. The interpretation and application of these constitutional system requirements in the adjudication of procurement cases have been varied - from the direct application of the constitutional requirements to the "proper" approach set out in the landmark 2014 judgement, Allpay Consolidated Investment Holdings (Pty) Ltd $v$ Chief Executive Officer of the South African Social Security Agency. ${ }^{2}$ The latter approach dictated interpreting the constitutional requirements of the public procurement system through the lens of administrative law and pronounced on elements of the balance required between the administrative or process-centric legal requirements and the system-centric nature of procurement procedures. This article revisits the foundational rationale for system-based procurement procedures and associated decision-making dynamics for their potential for finding a deterministic approach for the dual application of system and process legal requirements.

The importance of a deterministic approach for proceedings can be considered from two angles - the certainty of the procurer in the conformity of its own conduct and external certainty to diminish the risk of unnecessary challenge. Whether successful or not, challenges have far-reaching consequences for the state's ability to deliver. The clarity of compliant decision-making emerges as a goal over and above the goal of compliancy itself and hence a deterministic approach is argued to be fundamental to the design and operation of the public procurement system.

David Wickens. BSc (UCT) BSc (Hons) (UCT) LLB (UNISA), LLD (NWU). Independent technology procurement consultant, South Africa. Email: dave@wickens.co.za, https://orcid.org/0000-0002-0437-5251.

Constitution of the Republic of South Africa, 1996 (hereafter the "Constitution").

Allpay Consolidated Investment Holdings (Pty) Ltd $v$ Chief Executive Officer of the South African Social Security Agency 20141 SA 604 (CC) (hereafter Allpay). 


\section{Theoretical foundations underlying public procurement systems}

Procurement ${ }^{3}$ is the process of purchasing goods and services from an external party. It is a succession of logically related processes performed to identify, select, conclude and manage the contract to fulfil the purchasing need. Processes in turn are underpinned by methods and procedures informed and shaped by the policy of the procuring organisation.

\subsection{The nature of transactional procedures}

While the methods and procedures of general procurement vary considerably, free market operation drives competitive procurement. In public procurement, the instrument of open competition has fundamental value in promoting the objectives of accessibility, transparency, value for money, and is the procedure least susceptible to environmental weaknesses. Competitive tender procedures are based on an auction construct, establishing the basis for fair competition by publishing the system of rules for participants and the rules according to which the organiser will award the business. ${ }^{4}$

The motivation for the auction construct is to produce advantageous outcomes for the organiser in conditions of informational asymmetry between the organiser and participants. ${ }^{5}$ In terms of commitment theory, ${ }^{6}$ the pact to make an award on this basis is essential for attracting the best offers. Assuming competitive conditions and no collusion, variations of the auction construct can be shown to be theoretically optimal for different transactional circumstances. ${ }^{7}$ These variants are mirrored in formal public procurement tendering procedures, ${ }^{8}$ commonly the first-bid sealed-bid

$3 \quad$ Summarised from Arrowsmith, Linarelli and Wallace Regulating Public Procurement 1-2. Consumer Unity and Trust Society International Date Unknown http://www.cutsinternational.org/pdf/Executive\%20Summary.pdf.

$4 \quad$ McAfee and McMillan $1987 \mathrm{~J}$ Econ Lit 701. Competitive procurement procedures are nothing other than an auction procedure. Christie Law of Contract 42-43. The tender construct differs in that a tender is an invitation to submit offers and bids are offers to do business. As binding offers, the commercial dynamics remain the same.

$5 \quad$ McAfee and McMillan 1987 J Econ Lit 701.

$6 \quad$ Trepte Regulating Procurement 94. Trepte explains commitment theory as the mutual trust in the system binding both bidder and procurer as the incentive to submit the most attractive bid in the competition.

$7 \quad$ McAfee and McMillan 1987 J Econ Lit 702. See Carpineti, Piga and Zanza "Variety of Procurement Practice" 20.

$8 \quad$ Arrowsmith, Linarelli and Wallace Regulating Public Procurement 459-461. 
auction in the standard closed-envelope tender or the open-descending-bid auction in electronic reverse auction procedures. ${ }^{9}$

From a decision theoretical standpoint, auctions employ a normative procedure for decision-making, establishing the criteria for decision making without revisiting the criteria - or non-recursive decision-making. ${ }^{10}$ This procedure involves two distinct phases: the construction of the system for decision-making and execution of decision making in accordance with such a system. The system serves as the expression of the procurer's requirements for decision making by bidders and, as it is finalised prior to the receipt of offers, it represents the unbiased instruction for decision making in the award process that can be undertaken by disinterested agents. ${ }^{11}$

In execution, the value of the system construct for public procurement is that deviations from the published system provide an alert to interested parties of error, impropriety, bias or corruption. The first-bid sealed-bid model establishes a further procedural safeguard in prohibiting offers from being changed after submission and, as above, a deviation would be an alert to the potential of malfeasance. ${ }^{12}$

For these reasons, the first-bid sealed-bid model is well-entrenched as the default system for public procurement. ${ }^{13}$ For the purposes of this article, it is sufficient only to consider this, the most common procedure.

\subsection{System-based decision-making}

System-based decision-making procedures effect normative models for decision-making to select an option from available courses of action. Decision-making selection tasks are commonly framed as either decisions rejecting options from a set or decisions choosing options from the set. ${ }^{14}$ In practice, tender decision-making procedures consist of a combination of these approaches, respectively referred to as the processes of filtering and

$9 \quad$ While the auction type is termed an open ascending-bid, in procurement auctions this would involve descending price bids.

10 Csáki "Investigating the Decision Making Practice" 883. Descriptive models of decision-making typically search for alternatives by iteratively modifying the criteria with the "goals, objectives and value-relations according to options available" more closely resembling negotiation procedures.

11 Trepte Regulating Procurement 120.

12 This is not true of constructs such as electronic reverse actions.

13 Arrowsmith, Linarelli and Wallace Regulating Public Procurement 459-461. This does not preclude the existence or use of other procedures, but only in particular circumstances.

14 Soman "Framing, Loss Aversion and Mental Accounting" 393. 
selection. ${ }^{15}$ Filtering procedures generally precede selection procedures, as selection decision-making generally requires an exhaustive process, and to avoid bias in the binary rejection decisions. ${ }^{16}$

While promoting objectivity in public procurement, non-recursive systems of decision-making are designed without being calibrated in the actual circumstances of execution. This, coupled with a prohibition on changing the available options, is a scheme well removed from real-world decision making, and anomalies could reasonably be anticipated. An often-quoted example is the formal application of a filtering rule that rejects the best overall option for a minor mistake. ${ }^{17}$ Predefined selection methods, such as multi-attribute analysis algorithms, are similarly prone to flawed results. ${ }^{18}$ Practical realities, therefore, detract from the theoretical expectations of the first-bid sealed-bid model.

The motivation for rigid system-based decision-making principles in public procurement must be balanced with the obvious need to produce rational and effective decision-making, not only for the sake of the effectiveness of the transaction but for trust in the system. This is the dilemma - designing appropriate safeguards for inadequacies in system-based decision-making without negating the very purpose of a system. ${ }^{19}$

\subsection{The regulation of public procurement transactional systems}

To understand the operation of systems in the public procurement context, the interaction between two system components needs to be explained: the regulatory system and the transactional system. The public procurement environment is afflicted with vulnerabilities, for example, susceptibility to

15 De Boer, Labro and Morlacci 2001 EJPSM 77. These decisions exclude solutions from further consideration. Csáki and Adam 2010 Journal of Decision Systems 455. Exclusionary filtering decisions are made on the presence of negative attributes (or absence of positive attributes). The selection process is generally undertaken by ranking all (remaining) options in terms of their positive attributes (or the absence of negative attributes).

16 See Sanchez-Graells "Exclusion, Qualitative Selection and Short-listing" 99. In the UK, filtering decisions may be deferred to after the ranking process. This is vulnerable to "twisting" exclusions on formal grounds to retain the best offer. Also see Dekel and Schurr 2014 Rev $L$ \& Econ. It is shown empirically that recognised cognitive biases favour quantitative criteria.

17 Dekel 2008 PCLJ 239.

18 Generally, see Stilger Formulas. Different scoring rules produce different rankings for the same set of tenders using the same criteria and weightings. Commonly used scoring rules may even possess logical inconsistencies, for example the "ranking paradox". Further examples are provided in Chen 2008 JOPP 410-411 and De Boer et al "Analysis of Some Mistakes" 3-6.

19 Dekel 2008 PCLJ 262-265. 
corruption; $; 0$ the principal-agent problem, divergence of agency objectives from state procurement policies; ${ }^{21}$ collusion amongst market operators; ${ }^{22}$ and the performance of the procurement agents. The legal response is a regulatory framework establishing central control over executive procurers in terms of authority, standards and mechanisms to advance state policies and to combat environmental weaknesses. When a public procurer initiates a procurement transaction, the system it constructs (the transactional system) is governed by the rules and principles of this regulatory system. The focus of this regulatory system is internal, directly controlling the activities and decision-making of procuring entities. The regulatory system obviously cannot completely specify the content of transactional systems, as these will require individual transactional context. Conceptually, then, the regulatory system for public procurement is the source of authority for procuring entities, bounding decentralised discretion through a metasystem of rules and principles for the assembly of transactional systems aimed at achieving central objectives.

\subsection{Formulation and execution of transactional systems}

A transactional system must contain provisions detailing the specific commitments required of a bidder relating to the tender process, including the bid's form and substance, proof of its status, required declarations, performance offered and price. The content of the transactional system drives different bidder responses: simple responses (for example declarations; industry certifications; proof of tax-compliance; or history of past projects); timeous action (for example, participation, attendance and bid submission); and decision-making on the part of the bidder (for example, price, solution design choices or price-quality weighting). Any change to the transactional system after submission may have a retrospective effect, the most difficult to determine being on this last category of bidder decisionmaking.

Bidders have the greatest immediate interest in the procurer's compliance to the transactional system it has constructed. A departure from or change to the rules of the system is an alert to bidders of potential malfeasance. A retrospective effect may directly disadvantage a bidder, or indirectly through

\footnotetext{
$20 \quad$ Trepte Regulating Procurement 82.

21 Quinot "Promotion of Social Policy" 379. Quinot motivates the need for clear rules given the difficulty in assessing whether a procurement decision has been properly made if there is a broad set of horizontal policy objectives.

22 Owing to the nature of procedures such as public tendering, they are particularly susceptible.
} 
an advantage accorded to another bidder. A strict approach to departure provides grounds for challenge without the difficulty of having to show actual bias or bad faith in decisions, simply requiring a demonstration that the rules of the system were not followed. ${ }^{23}$ While an assistance to executive oversight, the invariable presence of a disappointed bidder makes this a vulnerability, if there is uncertainty in the binding nature of the transactional system.

Having given this foundational rationale for public procurement systems and decision-making, the next step is to investigate the South African legal context for public procurement systems and administrative decisionmaking.

\section{System-centric legal foundation}

\subsection{Section 217}

Section 217 of the Constitution establishes the fundamental requirements for an organ of state to conclude contracts: ${ }^{24}$ that it must do so in accordance with a system that is fair, equitable, transparent, competitive and cost-effective. Section 217 does not instruct specific legislative implementation, although it requires that if organs of state implement preferential policies, they must do so within the prescripts of a nationally legislated framework. The Preferential Procurement Policy Framework Act ${ }^{25}$ prescribes such a framework; specifically dealing with the implementation of policies contemplated in $217(2)$, without purporting to give legislative effect to the broader provisions of section $217(1) .{ }^{26}$ Although section $217(3)$ centralises aspects of policy control, the contemplation of organisational procurement policies indicates the constitutional intent for a decentralised environment. It is settled law that Section 217 has wide application to public

23 Dekel 2008 PCLJ 260-261. A theoretical basis for the rigid adherence approach.

24 Section 217 of the Constitution: "(1) When an organ of state in the national, provincial or local sphere of government, or any other institution identified in national legislation, contracts for goods or services, it must do so in accordance with a system which is fair, equitable, transparent, competitive and cost-effective. (2) Subsection (1) does not prevent the organs of state from implementing a procurement policy providing for- (a) categories of preference in the allocation of contracts; and (b) the protection or advancement of persons, or categories of persons, disadvantaged by unfair discrimination. (3) National legislation must prescribe a framework within which the policy referred to in subsection (2) must be implemented." Preferential Procurement Policy Framework Act 5 of 2000 (hereafter "PPPFA").

26 Preamble to the PPPFA. De la Harpe "Substantive and Objective Criteria in Preferential Public Procurement" 111. The provisions of secondary legislation issued under this Act regulating the evaluation mechanisms of the system may be interpreted to fall outside the scope of the Act. 
bodies and applies to the process of procuring goods and services from external bodies. ${ }^{27}$

Section 217(1) discloses three broad elements. When an organ of state contracts: a system must be in place; the system must be fair, equitable, transparent, competitive and cost-effective; and the organ of state must conduct its procurement activities in accordance with such system.

\section{2 ... a system}

\section{A system can be broadly defined $a^{28}$}

... a set of things working together as parts of a mechanism or an interconnecting network; a complex whole. A set of principles or procedures according to which something is done; an organized scheme or method.

Extended interpretations of the significance of the specific requirement for a system include the balancing of the five requirements, ${ }^{29}$ the broader allowance for non-tender procedures, ${ }^{30}$ and the application of the requirements to the full procurement lifecycle. ${ }^{31}$ These interpretations supplement but do not detract from the literal interpretation.

The section 217(2) derogation implies that a policy within the framework of the PPPFA cannot be constitutionally tested against the provisions of section $217(1) .{ }^{32}$ Given that a policy is an expression of principles and courses of action, it would form part of a system and hence the requirement that a system must be in place cannot logically prevent such

27 See for example Millennium Waste Management $v$ Chairperson Tender Board 2008 2 SA 481 (SCA) (hereafter Millennium); Steenkamp v Provincial Tender Board of the Eastern Cape 20073 SA 121 (CC) (hereafter Steenkamp). The courts have without further enquiry assumed the scope of "contracts for" to include the procurement process. Also see De la Harpe Public Procurement Law 26.

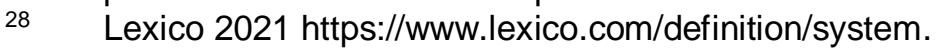

29 Bolton Law of Government Procurement 56. Bolton applies the meaning of "system" to describe the operation of the five principles, in that they operate together "as a whole".

30 Penfold and Reyburn "Public Procurement" 25-9. The authors accord significance to the requirement of "a system" to emphasise the accommodation of general procurement procedures, as opposed to the Interim Constitution's stipulation of a tender process.

31 De la Harpe Public Procurement Law 26. De la Harpe concludes that the term "system" motivates the application of the five requirements to the full lifecycle of procurement, in other words, the planning, procurement and contract management phases.

32 Policies may be tested against other provisions of the Constitution, but s $217(1)$ is specifically excluded. 
implementations of policy. ${ }^{33}$ Certain of the five $s 217(1)$ properties required of the system may well be argued to prevent such policies - for example that the system must be fair ${ }^{34}$ - and to the extent that a property may, would therefore not apply. The third element requiring that the organ of state contracts in accordance with the system is unaffected by section 217(2), as it simply demands the organ of state must follow a system - including its own policies. The three system-related elements of section $217(1)$ can be argued to persist except for the requirements of fairness, equity, transparency, competitiveness and cost-effectiveness to the extent that they may conflict with the PPPFA. ${ }^{35}$

\subsubsection{Legislative implementation}

As Section 217 does not instruct general legislative implementation, the constitutional requirements can be read as applicable to the provisions of all statutes and regulations governing the systemic activities of contracting for goods and services. In giving effect to Section 216 of the constitutional requirement for a National Treasury, ${ }^{36}$ the Public Finance Management $A c t^{37}$ empowers the National Treasury to make regulations and issue instructions concerning the framework "for an appropriate procurement and provisioning system which is fair, equitable, transparent, competitive and cost-effective". ${ }^{38}$ The PFMA assigns the responsibility to the accounting officer for the implementation of a procurement system "which is fair, equitable, transparent, competitive and cost-effective".39 The regulations to the PFMA further require the development and implementation of a supply chain management system that is "fair, equitable, transparent, competitive and cost effective".40 Local government statutes and regulations contain similar provisions: that a municipality's supply chain management policy

33 Barring the extreme possibility of a policy precluding the operation of a system. This would undoubtedly fail other tests of constitutionality.

34 By their nature, preferential policies could be argued to meet the requirements of substantive fairness but would preclude simple horizontal fairness.

35 The requirements of transparency and macro cost-effectiveness may be argued to persist. Wickens Meaning and Application of Cost-effectiveness 79-80, 125-126. Section 216 of the Constitution requires legislation to establish a National Treasury that is constitutionally mandated to enforce compliance with measures to ensure transparency and control of expenditure. Public Finance Management Act 1 of 1999 (hereafter "PFMA").

Subsection 76(4)(c) of the PFMA.

Subsection 38(a)(iii) of the PFMA.

Regulations 16A3.1 and 16A3.2 of the Regulations to the PFMA (GN R225 in GG 27388 of 15 March 2005 (hereafter "PFMAR"). The supply chain management system must also be consistent with the PPPFA and the Broad-based Black Economic Empowerment Act 53 of 2003. 
must be implemented in a way that is fair, equitable, transparent, competitive and cost-effective. ${ }^{41}$

Various regulations restate the constitutional requirements directly to procurement procedures. For example, the Treasury Regulations ${ }^{42}$ effectively re-phrase the requirements of Section 217 for public private partnership procedures. ${ }^{43}$ This is also found in specific sectoral contexts, for example electricity procurement procedures: "the Minister may ...require that new generation capacity must ... be established through a tendering procedure which is fair, equitable, transparent, competitive and costeffective." 44

The Section $217(1)$ provisions have been implemented in primary and secondary legislative procurement instruments, mostly in the form of duties to implement a copy-out of the constitutional requirements. The legislative approach to the constitutional provisions can be regarded as broadly painting procurement-related frameworks, provisioning systems, supply chain management systems down to tender procedures with a restatement of the requirements of section $217(1)$. The conclusion is that the legislative interpretation of the "system" is in its widest sense, from administrative and organisational systems to the systems governing individual transactions.

\subsubsection{Judicial interpretation}

The judicial interpretations of the Section 217 system are significant to its practical application. In Steenkamp ${ }^{45}$ - one of the earliest procurement disputes under the final Constitution - the Section 217 system was interpreted to be the transactional system:

... the tendering system [an organ of state] devises must be fair, equitable, transparent, competitive and cost-effective.

The view of the system has not been consistent. For example, in Chief Executive Officer, SA Social Security Agency v Cash Paymaster Services

41 Section 65(2)(i) of the Local Government: Municipal Finance Management Act 56 of 2003.

42 Regulation 16 of the PFMAR.

43 Regulation 16.5 of the PFMAR: "The procurement procedure - (a) must be in accordance with a system that is fair, equitable, transparent, competitive and costeffective; and (b) must include a preference for the protection or advancement of persons, or categories of persons, disadvantaged by unfair discrimination in compliance with relevant legislation."

44 Section 46(1) of the Electricity Regulation Act 4 of 2006.

$45 \quad$ Steenkamp para 33. 
(Pty) $L t d,{ }^{46}$ the extent of the constitutional system was interpreted to be the legislative and regulatory system. The Constitutional Court in Allpay expanded the view taken by Steenkamp, holding that the transactionspecific instructions issued by an organ of state were binding, explicitly including internal rules and circulars, National Treasury instruction notes and the published tender document, which make up the enforceable framework for the tender process. ${ }^{47}$ The prevailing view of the Section 217 system can then be understood as the full extent of the legislation, regulation, rules, instructions and procedures published by the procuring entity applicable to a transaction.

On several occasions the courts have interpreted the Section 217 requirements to extend to the tender process. ${ }^{48}$ This interpretation is difficult to support as a compliant process is neither a necessary nor a sufficient condition of acting in accordance with a compliant system. ${ }^{49}$ Conversely, the rules of an otherwise compliant but incomplete system may be shown not to result, for example, in a fair process through its reliance on the decisions made at the time of execution. ${ }^{50}$ The first requirement for a valid process should be conformance with the system, the subject of the next section.

\section{3 ... in accordance with}

The broad legislative implementation of the system specifies duties to implement frameworks and regulations specifying general procedural rules to be applied during a tender process as well as rules for the transactional

$46 \quad$ Chief Executive Officer, SA Social Security Agency $v$ Cash Paymaster Services (Pty) Ltd 20132 All SA 501 (SCA) para 15. "This implies that a 'system' with these attributes has to be put in place by means of legislation or other regulation. Once such a system is in place and the system complies with the constitutional demands of section 217(1), the question whether any procurement is 'valid' must be answered with reference to the mentioned legislation or regulation."

$47 \quad$ Allpay para 38. Together these "constituted the legally binding and enforceable framework within which tenders had to be submitted, evaluated and awarded". Also see Volmink 2014 APPLJ 45.

$48 \quad$ Millennium para 4. See Minister of Social Development $v$ Phoenix Cash \& Carry Pmb CC 20079 BCLR 982 (SCA) para 2. Interestingly this is quoted with approval in Allpay para 92. IMVUSA Trading 134CC v Dr. Ruth Mompati District Municipality 2008 ZANWHC 46 (20 November 2008) para 7: "The tender process must be fair, transparent, competitive and cost-effective". [own emphasis]

Lexico $2021 \mathrm{https} / / / \mathrm{www}$. lexico.com/definition/process. A process is a "series of actions or steps taken in order to achieve a particular end". This does not incorporate the dimension of procedure according to which the process must be performed. Westinghouse Electric Belgium Societe Anonyme v Eskom Holdings (Soc) Ltd 2016 1 All SA 483 (SCA) para 34. The court considered the retrospective effect of introducing new criteria during the evaluation. 
systems. While the accordance of the lower order rules of the system with the higher order rules is a question of legality, it is also a requirement of the constitutional system working as a complex whole.

Organisational systems are prescribed in the form of supply chain management systems. The organisational aspects of the system include systems of committees, the rules for their formation and systems of authorisation and decision-making. ${ }^{51}$ Organisational policies are also included in the scope of the system, although the legislative implementation in the PPPFA and regulations prescribe a narrow framework with little room for the broader development of organisational policies promoting the objects of section $217(2)$.

Once developed and published, the transactional system defines formal and substantive rules and procedures for decision-making in the transaction. Provided the transactional system has been constructed in accordance with the superordinate regulatory and institutional systems, the constitutional instruction is clearly a matter of carrying out the procurement in accordance with the transactional system.

While the general model for tender procedures establishes the rationale for the observance of the pact with tenderers to award business, Section 217 establishes a constitutional expectation that the system will be followed.

\section{4 ... that is fair, equitable, transparent, competitive and cost- effective}

There is consensus that the requirements have few absolute, direct and concrete system implementations and require interpretation and evaluation in the circumstances of the transaction. ${ }^{52}$ The requirements of fairness, equitableness, transparency, competitiveness and cost effectiveness are stated conjunctively, but by their contrasting natures, individual achievement may limit the achievement of others. ${ }^{53}$ In practice, and in differing transactional circumstances, the requirements may support or

51 See, for example, Bolton 2009 PELJ 89-91

52 See, for example, Bolton Law of Government Procurement ch 5-8; Wickens Meaning and Application of Cost-effectiveness ch 3, De la Harpe Public Procurement Law 281-290.

53 Dekel 2008 PCLJ 243-244. Dekel provides the example of exacting fairness excluding the most cost-effective bid. 
place limitations on one another, and therefore a balancing of the requirements is implied. ${ }^{54}$

Although the five requirements can be described as general procurement principles, they are requirements of the system. As no particular part of the system is specified, these are requirements of the whole system - regulatory systems and product transactional systems. Given its meta-nature, a shortfall in regulatory system provisions would be legally actionable only in the event of consequential shortfalls in a transactional system. A regulatory system should aim to compel aspects of fairness, equitableness, transparency, competitiveness and cost-effectiveness in transactional systems but must not have the effect of preventing the attainment of these attributes in transactional systems.

Constitutional compliance with the statutory components of the regulatory system is subject to a legislative process. Executive regulation is also subject to due process and comment before being brought into effect. In both cases, the constitutional compliance of policy or the functional aspects of the regulatory system are widely tested. In contrast, the extent to which an organ of state may freely consult with the market to test the compliance of the transactional system is limited by considerations that may affect the compliance of the transactional system itself. ${ }^{55}$ However, after publication the procuring entity may receive representations regarding the transactional system. There is therefore a limited window for the procurer to issue corrections, clarifications, or even material changes to the transactional system, to cure identified defects prior to the close. ${ }^{56}$

The requirements of being fair, equitable, transparent, competitive and costeffective are necessary for the compliance of the system but obviously not a sufficiency. The requirements must be understood together with other constitutional provisions. ${ }^{57}$ The basic values governing public administration impose, inter alia, requirements of efficiency, the economic and effective use of resources; the fair provision of services without bias; accountability;

54 Bolton Law of Government Procurement 56; Penfold and Reyburn "Public Procurement" 25-12.

55 Consultation with a party generally precludes the party's later participation, although this is not always clear cut and will depend on the level of involvement. Aurecon South Africa (Pty) Ltd v City of Cape Town 2015 ZASCA 209 (9 December 2015) paras 41-44. A common example is an amendment to the closing time. The process of change, or refusal to change, is discussed in para 0 below.

57 Steenkamp para 33. "This requirement must be understood together with the constitutional precepts on administrative justice in section 33 and the basic values governing public administration in section 195(1)." 
and transparency - and to the extent that these apply, they may be read as additional requirements of the system. Even if a system possesses all the required properties, the transaction is subject to a further test - that the system's rules in execution meet the standards of a fair administrative process.

\section{Process-centric legal foundation}

\subsection{Section 33 and the PAJA}

Section 33 of the Constitution sets out the fundamental right to just administrative action. ${ }^{58}$ The Promotion of Administrative Justice Act ${ }^{59}$ gives content to the right, and hence the justiciability of the constitutional provision is generally considered in terms of these legislative provisions. ${ }^{60}$ In terms of the PAJA, administrative action means a decision (or failure to take a decision) of an administrative nature, making a determination or award in terms of an empowering provision, where an empowering provision could be in terms of law, agreement, instrument or other document. ${ }^{61}$ The activities undertaken as part of public procurement require decisions in the exercise of a public power or in the performance of a public function, which place these within the ambit of administrative action. ${ }^{62}$ Decisions, particularly those taken during the procurement phase of the life cycle, have been well established as constituting administrative action; for example, the

Section 33 of the Constitution:

"33. Just administrative action

(1) Everyone has the right to administrative action that is lawful, reasonable and procedurally fair.

(2) Everyone whose rights have been adversely affected by administrative action has the right to be given written reasons.

(3) National legislation must be enacted to give effect to these rights, and must

(a) provide for the review of administrative action by a court or, where appropriate, an independent and impartial tribunal;

(b) impose a duty on the state to give effect to the rights in subsections (1) and (2); and

(c) promote an efficient administration."

59 Promotion of Administrative Justice Act 3 of 2000 (hereafter "PAJA").

60 Quinot 2010 Annu Surv SA L 41. The principle of subsidiarity should place reliance first on the legislation enacted to give effect to a right, unless the legislation is itself in question.

Section 1 of PAJA, definitions of decision, empowering provision and administrative action. than the activities of public procurement and in terms of the entities to which s 217 applies. 
call for and adjudication of tenders, ${ }^{63}$ the decision to award a tender ${ }^{64}$ and the decision not to award a tender. 65

\begin{abstract}
Allpay sets out the general administrative law construct for bids (as representations) in a public tender process: 66

In the context of a tender process, the tender documents give notice of the proposed administrative action, while the responding bids in effect constitute representations before the decision is made. Adequate notice would require sufficient information to enable prospective tenderers to make bids that cover all the requirements expected for the successful award of the tender.
\end{abstract}

This construct accords with the view that the notice of the tender, the tender documentation and each further notice in the bid preparation phase, constitute notice of administrative action culminating in the award decision. ${ }^{67}$ This gives context to the bids as required representations, but does not exclude the possibility of representations outside this construct.

\title{
4.2 ... lawful, reasonable and procedurally fair
}

The requirement of lawfulness of administrative action is first a matter of legality: that the action is taken in accordance with the powers granted. Material errors of law or fact will render the action reviewable where the materiality of such errors is determined by the correspondence of the result with the purpose of a provision, rather than by strict compliance. ${ }^{68}$ Lawfulness extends to the proper exercise of discretionary powers, enabling the review of arbitrary or capricious decisions, or those made with an ulterior motive or in bad faith, and the failure to act or act timeously.

Reasonableness requires that there is a rational or objective basis that justifies the decision and that the decision is connected to the purpose for which it was taken, the empowering provisions, the information available

Transnet Limited v Goodman Brothers (Pty) Ltd 20012 BCLR 176 (SCA) 43; Millennium para 21.

Umfolozi Transport (Edms) Bpk v Minister van Vervoer 19972 All SA 548 (A) 552j553a.

Logbro Properties CC v Bedderson 20032 SA 460 (SCA) para 5.

Allpay para 90. While this is a general construct, also see Viking Pony Africa Pumps

(Pty) Ltd t/a Tricom Africa v Hidro-Tech Systems (Pty) Ltd 20112 BCLR 207 (CC) para 37. The application of administrative law cannot be determined in the abstract and must be confirmed by the facts of each case.

Hoexter Administrative Law 372.

Hoexter Administrative Law 294. The point of a judicial enquiry is establishing whether the relevant conduct is valid in relation to the requirement and "labels such as peremptory and directory are secondary - a means to an end and not an end in themselves." 
and the reasons given. ${ }^{69} \mathrm{~A}$ further element of reasonableness - that of proportionality - is required to avoid an "imbalance between adverse and beneficial effects". ${ }^{70}$

The PAJA gives effect to the right to procedural fairness by requiring adequate notice of the nature and purpose of the proposed administrative action; a reasonable opportunity to make representations; a clear statement of the administrative action; adequate notice of any right of review; internal appeal; and the right to request reasons. The PAJA permits a departure from any of these requirements if it is reasonable and justifiable, taking into account all relevant factors. ${ }^{71}$

The law that applies to the process, or the system in execution, therefore imposes additional requirements for system-based decision-making both on procedural components of the system and on the effects of the system.

\section{System and process requirements in the procurement lifecycle}

The test of compliance with the constitutional system requirements is not whether an ensuing process is fair, equitable, transparent, competitive and cost-effective, nor is the process required to be fair, equitable, transparent, competitive and cost-effective. Conversely lawful, reasonable and procedurally fair procurement decisions are not dependent on a fair, equitable, transparent, competitive and cost-effective system. The legal standard for administrative decision-making is clearly different from the standard governing the procurement system of decision-making although both will apply during the lifecycle of the transaction.

\subsection{Formulation of the regulatory system}

A system working as a "complex whole" demands the accordance of lowerorder rules of the system with those of a higher order. Bringing regulation into force is administrative action and the implementation of lower-order

69 Section 6(2)(f)(ii) PAJA. Hoexter Administrative Law 342 This falls short of a requirement that it should be the correct decision.

Hoexter Administrative Law 343.

These factors include the objects of the empowering provision; the nature and purpose of, and the need to take, the administrative action; the likely effect of the administrative action; the urgency of taking the administrative action or the urgency of the matter; and the need to promote an efficient administration and good governance. 
regulation is valid within the ambit of empowering provisions only. ${ }^{72}$ At this level, the process-centric aspects of system construction are congruent with the system-centric provisions in ensuring the integrity of a complex system construct. ${ }^{73}$

\subsection{Formulation of the transactional system}

The regulatory meta-system will require decision making on the part of the public body in formulating the rules, procedures and criteria specific to a particular transactional context. Statutes, regulation, notices and guidelines are supplemented by the requirements of the public body's own supply chain policy and organisational rules about the committees, their functioning and composition to make up this regulatory system governing the construction of the transactional system.

While formal aspects of system construction, for example the regulatory requirement for a separated committee system, can be enforced through aspects of lawfulness, the reasonableness of decisions in its construction provides a legal basis for ensuring the absence of bias in proceedings, perceived or otherwise. Involving interested parties in the construction of the system may not result in an unfair system but the process-centric safeguards ensure integrity in its construction. ${ }^{74}$ The process of construction is therefore supplemented and strengthened by administrative law requirements to enforce the intent of the regulatory system.

The compliance of the transactional system in terms of procedural fairness will include adequate notice - sufficient time to prepare the bids; representations - ability to make representations, which may include the ability to make representations prior to bid submission; the procedure for review; and notice of the right to request reasons. The PAJA therefore

72 Sizabonke Civils CC t/a Pilcon Projects v Zululand District Municipality $2010 \mathrm{JOL}$ 25535 (KZP) paras 9-11. This dealt with regulations permitting the evaluation of quality in the scoring rules in the transactional system. In casu, the regulations were judged ultra vires as the empowering statute, the PPPFA, had not authorised such an evaluation scheme.

73 Hoexter Administrative Law 256-258. Lawful administrative action extends to the making of regulations, requiring that the regulator is authorised and empowered to make regulations constituting the regulatory system in accordance with empowering provisions.

74 Consultation or assistance in drawing up specifications by a party generally precludes their later participation, although this is not always clear cut and will depend on the level of involvement. Aurecon South Africa (Pty) Ltd v City of Cape Town 2015 ZASCA 209 (9 December 2015) paras 41-44. 
imposes specific systemic requirements over and above the general Section 217 requirements.

\subsection{Publication of the transactional system}

From a theoretical auction aspect, the system to which the participants and the procuring entity alike will have committed is defined at the time at which the bids must be submitted. On this basis, the procurer may make changes to the system before closing, and could do so without prejudice, as the bidders would not have finalised their decision-making nor made their decisions known by way of response. ${ }^{75}$

As proposed in Allpay, the publication of the tender documents gives notice of the intended administrative action that initiates the execution phase. The public body may receive representations making it aware of circumstances that render the system non-compliant and should issue clarifications and corrections in response ${ }^{76}$ It may also change the rules of the system, for example by entertaining requests for extensions of time prior to the closing of the tender. In Menzies Aviation South Africa (Pty) Ltd v SAA (Pty) Ltd, ${ }^{77}$ Menzies, a non-incumbent bidder, made representation for additional time to prepare its bid. The short time allowed and paucity of information available was decided to be prejudicial to Menzies, and the process held to be procedurally unfair. ${ }^{78} \mathrm{Had}$ the procurer acceded to Menzies's request during the bid preparation phase, it could have timeously cured the offending system element.

In South African Post Office Ltd v Chairperson of Western Cape Provincial Tender Board, ${ }^{79}$ a challenge was mounted after the award because the high weighting of price had not been published. The court commented that such shortfalls should not be raised after the event, and any lack of transparency apparent after publication should be the subject of representation prior to the close. ${ }^{80} \mathrm{~A}$ relevant question is whether an obligation could exist on

75 This is subject to any bids submitted before the closing time being returned unopened. See Sanyathi Civil Engineering \& Construction (Pty) Ltd v eThekwini Municipality, Group Five Construction (Pty) Ltd v eThekwini Municipality 20121 All SA 200 (KZP) para 55. This may involve a declaratory order.

76 For examples the Bidder's Notices in Allpay.

77 Menzies Aviation South Africa (Pty) Ltd v SAA (Pty) Ltd 2010 JOL 24726 (GSJ) para 18 (hereafter Menzies).

78 Menzies paras 40-42.

79 South African Post Office Ltd v Chairperson of Western Cape Provincial Tender Board 20015 BCLR 500 (C) para 20.

80 The procurer's argument that the reason for the non-disclosure of the details of the weighting was that "tenderers were thereby discouraged from concentrating on the criteria which carry greater weights at the expense of others" was accepted as this 
potential bidders to make representations regarding the compliance of the system prior to the close, and whether the failure to do so could constitute a waiver of their right to object on these grounds at a later stage. ${ }^{81}$ There may be merit in this proposition to improve the compliancy of the transactional system before it is put into action.

\subsection{Process of transactional system execution}

The foundations of the tender model and the constitutional instruction are congruent: the process of executing the tender must be carried out in accordance with the transactional system. However, what if imperfections in the transactional system are exposed only during execution? Three categories are discussed, broadly corresponding to the three elements of Section 217.

\section{$5.5 \quad$... a system}

The transactional system may not define clear rules for dealing with particular situations. This could be manifest in the omission of a required element of the operation of the system - a shortfall in system completeness. This is distinguished from situations where a material element of the system is present but not disclosed and a system ambiguity (transparency), and the introduction of a new rule (decisions outside the system).

An example of the omission of a required system element was provided in Envitech Solutions (Pty) Limited $v$ Saldanha Bay Municipality, ${ }^{82}$ where the method for aggregating evaluator scores had not been specified. In theoretical auction terms, the extent of the compromise to the pact would be the extent to which the scheme adopted in execution may have influenced bidder decision-making had it been included in the system, or its retrospective effect. In casu, it was decided that it was sufficient for the process followed to comply with the standard of being rationally connected to the purpose. ${ }^{83}$ While this is not equivalent to a retrospectivity test, in the absence of a representation during bid preparation, a bidder's expectation should be that decision-making would be congruent with the tender's

had been communicated to the tenderers. This indicates the permissibility of reduced transparency if there is an acceptable reason for its reduction.

81 Hoexter Administrative Law 389.

82 Envitech Solutions (Pty) Limited v Saldanha Bay Municipality 2015 ZAWCHC 108 (13 August 2015) (hereafter Envitech).

83 Envitech paras 78-82. In execution, the procuring entity averaged evaluator scores to arrive at a single score. The standard of reasonableness in the method chosen must meet the criterion of being rationally connected to the purpose. 
purpose. On the one hand, system incompleteness could be regarded as a shortfall in meeting the constitutional requirement for a system. On the other, the system-centric legal standards could be regarded as not extending to this degree and should be safeguarded by process-centric legal standards. In terms of a deterministic approach, if a duty were to exist on the bidder to make representations regarding issues important to its decision making prior to submission, the published system needs to comply only with the latter standard of completeness.

Another system-related shortfall is a system's explicit deference to discretion. System-controlled decision-making could be argued to depend on some level of discretion, but at the point critical decision-making is left to loosely bounded discretion, essential properties of a system cease to exist. The regulatory system has provided a discretionary loophole in the provisions of section 2(1)(f) of the PPPFA which (in peremptory terms) instructs that the tender be awarded to the highest points scorer unless objective criteria exist. ${ }^{84}$ This broad inclusion of any objective criteria that may be found to exist at the time of selection was required by the regulations until 2017. As a peremptory provision of the regulatory system, it was a tacit provision of every transactional system, proving fertile ground for disputes regarding both its application ${ }^{85}$ and its non-application. ${ }^{86}$ The current regulations align to the requirement of "a system" in that it affords the discretion to include objective criteria, provided notice is given in the transactional system, and does not simply insist on considering new criteria for decision making during execution. In the slew of disputes relating to the exercise of discretionary decision-making in terms of 2(1)(f), the PAJA process safeguard generally averted the consequences of capricious decision-making. Despite this protection, a system providing for such a wide degree of discretion in execution must be thought to weaken the capacity

84 Section 2(1)(f) of the PPPFA. Reg 7(1) of the Preferential Procurement Regulations, 2011 (GN R502 in GG 34350 of 8 July 2011) simply referred back to s 2(1)(f) of the PPPFA. The Preferential Procurement Regulations, 2017 (GN R32 in GG 40553 of 20 January 2017) has introduced welcome changes requiring the publication of criteria that may be considered in the transactional system, thus insisting on properties that could be regarded as being closer to a "system". Westinghouse Electric Belgium Societe Anonyme v Eskom Holdings (Soc) Ltd 20161 All SA 483 (SCA) para 34. Foreknowledge of the criteria is a matter of fairness.

85 For example, Grinaker LTA Ltd v Tender Board (Mpumalanga) 20023 All SA 336 (T) paras 40-41.

86 In Rainbow Civils CC v Minister of Transport and Public Works, Western Cape 2013 ZAWCHC 3 (WCC) paras 110-114. The public entity was judged to have erred for not having considered functionality directly as such an objective criterion. 
for a deterministic verification of proper decision-making, and therefore be an invitation to challenge.

\title{
5.6 ... that is fair, equitable, transparent, competitive and cost- effective
}

\subsubsection{Shortfalls in the required qualities of the system}

In Allpay, the Constitutional Court put forward the legal position regarding imperfections in the transactional system.

\begin{abstract}
The [legislative framework for procurement policy under section 217] thus provides the context within which judicial review of state procurement decisions under PAJA review grounds must be assessed. The requirements of a constitutionally fair, equitable, transparent, competitive and cost-effective procurement system will thus inform, enrich and give particular content to the applicable grounds of review under PAJA in a given case. The facts of each case will determine what any shortfall in the requirements of the procurement system - unfairness, inequity, lack of transparency, lack of competitiveness or cost-inefficiency - may lead to procedural unfairness, irrationality, unreasonableness or any other review ground under PAJA. ${ }^{87}$
\end{abstract}

A review under PAJA would naturally consider system non-compliance in its effect on the rights to lawful, procedurally fair, rational, reasonable decision-making. This pronouncement does not preclude a direct enquiry into the constitutional compliance of the system, but a standard would still be required to decide the balance of the five requirements. In South African Post Office Ltd $v$ Chairperson of Western Cape Provincial Tender Board, ${ }^{88}$ the non-disclosure of the high weighting of price did not fall foul of the requirement of transparency because there was a rational connection to, and therefore appropriately balanced in the circumstances with, the pursuit of effectiveness (cost-effectiveness). ${ }^{89}$ In Loliwe CC t/a Vusumzi Environmental Services $v$ City of Cape Town ${ }^{90}$ the lack of transparency in the requirement that the completion of every item in a table was required for the purposes of scoring had "detracted materially ... from the fairness and transparency of the system used" as bidders had unwittingly fallen foul of the requirement. In contrast to the earlier example, there was no balancing requirement and no rational purpose could be argued for the lack of

\footnotetext{
$87 \quad$ Allpay para 43.

88 South African Post Office Ltd v Chairperson of Western Cape Provincial Tender Board 20015 BCLR 500 (C) para 16.

89 The respondent's argument for the non-disclosure of weight was that "tenderers were thereby discouraged from concentrating on the criteria which carry greater weights at the expense of others."

90

Loliwe CC t/a Vusumzi Environmental Services v City of Cape Town 2012 ZAWCHC 162 (6 July 2012) para 26.
} 
transparency. So even in a direct system enquiry, the rationality of the system's effect provides a standard for the question of balance.

\subsubsection{Circumstances forcing a shortfall in the qualities of the system}

Rather than a system shortfall per se, circumstances unforeseen at the time of its formulation could affect its compliance. In Premier, Free State $v$ Firechem Free State (Pty) Ltd, ${ }^{91}$ knowledge held by one tenderer which allowed it to price its bid without components only it knew to have been completed was observed as having the effect that "competitiveness is not served by only one or some of the tenderers knowing what is the true subject of tender. That would deprive the public of the benefit of an open competitive process." This is an example where the values required of the system conversely "enrich" the requirements for administrative justice.

\section{7 ... in accordance with}

While Section 217 establishes a constitutional expectation of adherence to the system, the administrative legal requirement that lawful, reasonable decisions be made in a procedurally fair process is less rigid.

A departure from the system is an alert to impropriety and a strict adherence approach overcomes the burden of proving unreasonableness, bias or bad faith in decisions, simply requiring evidence that the rules of the system were not followed. ${ }^{92}$ The counter-argument is that reasonable decisions should be made in prevailing circumstances and not fettered by a preordained system.

In Allpay the Constitutional Court pronounced on deviations from the system: ${ }^{93}$

Compliance with the requirements for a valid tender process, issued in accordance with the constitutional and legislative procurement framework, is thus legally required. These requirements are not merely internal prescripts that SASSA may disregard at whim. Once a particular administrative process is prescribed by law, it is subject to the norms of procedural fairness codified

Premier of the Free State Provincial Government v Firechem Free State (Pty) Ltd 20004 SA 413 (SCA) para 47.

92 Dekel 2008 PCLJ 260-261. Dekel puts forward the theoretical basis of the rigid adherence approach. Sewpersadh and Mubangizi 2017 PELJ 17. The implication of concentrating on adherence or departure from the rules may have led to a reluctance to admit evidence of underlying corruption.

93 Allpay para 40; s 3(4)(a) of PAJA. PAJA contemplates departures from the system in the circumstance if it is reasonable and justifiable and the administrator has taken all relevant factors into account, including the objects of the empowering provision and the nature and purpose of the need to take the decision. 
in PAJA. Deviations from the procedure will be assessed in terms of those norms of procedural fairness. That does not mean that administrators may never depart from the system put into place or that deviations will necessarily result in procedural unfairness. But it does mean that, where administrators depart from procedures, the basis for doing so will have to be reasonable and justifiable, and the process of change must be procedurally fair.

The court considered two aspects of adherence: (1) that the system cannot be disregarded "at a whim" but that administrators may depart from it if the departure is reasonable and justifiable and the process of change is procedurally fair and (2) if the deviations relate to procedure, it is subject to the norms of PAJA. The elements of procedural fairness address specific elements of procedure in the system: sufficient notice; opportunity to make representation; clarity of the statement; notice of the right to review; and the right to request reasons. While the court accepted that deviations may "betoken a deliberately skewed process",${ }^{94}$ strict and formal adherence to the provisions of the system that determine the compliance of a bidder are subject to a number of factors, but centrally to the question of purpose. ${ }^{95}$

\subsubsection{Unintentional departures}

There can be various proximate reasons for an unintentional departure, including errors of fact ${ }^{96}$ or errors of law. ${ }^{97}$ The Allpay position above would seem to exclude a departure in error from ever being reasonable and justifiable or the process of deviation from being procedurally fair. At odds with this logic, the Constitutional Court considered "irregularities" to invoke a different test, one of materiality, being assessed against the purpose of the tender requirements. Although technically a departure from the system, an unintentional departure, or irregularity, would appear to invoke a less rigorous procedure for ex post validation.

\subsubsection{Intentional departures}

The administrative decision standard of congruency with the purpose of a system provision suggests that the procurer may depart from the system intentionally if a provision does not serve the purpose of the system. An

\footnotetext{
94 Allpay para 27. "Deviations from fair process may themselves all too often be symptoms of corruption or malfeasance in the process." Allpay para 30. Here compliance refers to the compliance of a bidder and not the compliance of the administrator in enforcing the provision.

96 For example, Trencon Construction (Pty) Limited $v$ Industrial Development Corporation of South Africa Limited 20155 SA 245 (CC) para 64. The escalated price should not have been considered. ZAFSHC 186 (28 October 2016) para 33. The scoring was conducted incorrectly.
} 
immediate problem is how the purpose of a system can be determined other than by its provisions. Assuming it can be determined from other elements of the system, could such a system be compliant? A system containing a provision incongruent with the system's purpose would generally produce a result different from that intended, and hence the administrative decision standard would not be at odds with the requirements of an ideal system.

An innocent bidder mistake ${ }^{98}$ provides a good example. A filtering decision based on an erroneous bidder response may not serve the substantive purpose of the system. If sufficiently disproportional, this could be argued to be a failure to meet the constitutional standard of system fairness in the vertical sense and a determination of invalidity may be reached albeit along different lines of legal reasoning. Regardless, this is an unenviable position for the procurer to find itself in during the execution of the system. ${ }^{99}$ In the case of bidder error, system provisions could avoid this, ${ }^{100}$ for example, by allowing controlled rectification to represent the bidder's demonstrable intent, status or history correctly without allowing modification to the bidder's original decision-making. Without such assistance in the system, the procurer has to weigh the consequences of enforcing the system versus departing from the system.

To invalidate proceedings, a procurer's failure to depart from the system could be viewed as the inverse of the consequence of its adherence, invalidating proceedings. However, the failure to depart from the system goes further to suggest that there is a positive aspect to the "ever-flexible duty to act fairly". ${ }^{101}$ Not only would a departure be lawful in certain circumstances but there is an expectation that the administrator should do so to validate proceedings. ${ }^{102}$

The question then becomes what departures can legitimately correct system shortfalls? A departure from a system can also be viewed as replacing a published provision with a new provision. This new provision, like any other provision of the system, would have to be consistently applied

\footnotetext{
98 See for example Millennium para 6. The bidder failed to sign a declaration of interest.

99 Volmink 2014 APPLJ 54. Without a clear process, procurement officials would be expected to resolve complex legal issues during evaluation.

100 This is permitted in other jurisdictions. For example, in the United Kingdom, reg 56(4) of the Public Contracts Regulations 2015, SI 2015/102. The contracting authority is given the discretion to allow rectification provided it is in "full compliance with the principles of equal treatment and transparency".

101 Logbro Properties CC v Bedderson 20032 SA 460 (SCA) para 8.

102 Millennium para 21. It was held erroneous to think an omission of a signature amounted to a failure to comply with the provision, and therefore inconsistent with PAJA.
} 
but, in order not to prejudice any bidder materially, may not have a retrospective effect on any bidder's decision-making.

A departure from the published system could also take the form of supplementary provisions, for example criteria not published in the system. As a general principle, the consideration of extraneous information represents a departure from the system that would have a retrospective effect. $^{103}$ This does not extend to additional procedures to verify claims a bidder has made - Allpay affirmed that not only is it permitted, but it is required in the case of claims to broad-based black economic empowerment status. ${ }^{104}$

An intentional departure requires that the process of change must be "procedurally fair". ${ }^{105}$ In the case of supplementary provisions falling outside those for the verification of bidder claims, the affected bidder must be afforded the opportunity to make representations. It is less clear what is required in the instance of a departure introducing weaker provisions, as the parties potentially prejudiced would be those not directly affected by the change.

By design, any departure from the system will invite enquiry. Unintentional departures will be judged on their materiality in terms of whether the purpose of the system was ultimately served and, in this respect, the process-centric legal standards support those serving the system. The question of an intentional departure from the transactional system is a complex balance of the principles of "flexibility versus uniformity", ${ }^{106}$ "weighing of values"107 or fettering vs principles of system operation. ${ }^{108}$ A departure must be motivated by a shortfall in the system exposed in the circumstances that would not serve the purpose of the system and must not have a prejudicial retrospective effect on bidders. If so, a departure cannot cure the system. Departures in the form of supplementary provisions can be argued always to have a retrospective effect, but those introduced into the system to complete the system will be permitted if reasonable and if they serve the purpose of the system. The conclusion is that a deterministic

103 Simunye Developers CC v Lovedale Public FET College 2010 ZAECGHC 121 (ECG). Also see Quinot 2010 Annu Surv SA L 62. Permissible unpublished criteria would be those expected by the bidder to be used in decision-making without an opportunity to make representations.

Allpay para 40

Volmink 2014 APPLJ 44.

Dekel 2008 PCLJ 256-259.

Hoexter Administrative Law 319. 
method of choosing the right course of action once a system shortfall has been exposed in flight may be elusive, and that the greatest effort should be directed at constructing a transactional system that is consistent with the demands of administrative decision making.

\section{Conclusion}

The process-centric framework of law operates in concert to ensure the order of the overall system in its formulation, and provides a legal standard for establishing the compliance of the system, including the balance of the constitutional requirements of the system. It provides a standard for decision making where the system is incomplete and for evaluating discretion exercised in weakly formulated systems. The process-centric legal framework imposes additional requirements on the system in operation, effectively rounding disproportionately sharp edges of the system and providing the means for the review of the procurement proceedings.

From a process-centric departure point, the imposition of a non-recursive decision-making system represents a fettering of discretion in administrative decision-making. This is well justified by the dynamics sought in procurement auctions: the pursuit of objectivity and countering the weaknesses endemic to the procurement environment. The proposition that the PAJA tests are "enriched" by the constitutional procurement provisions acknowledges the fundamental value of a system in procurement proceedings but maintains the primacy of the process-centric legal requirements.

The thrust of administrative law is directed at the detection and remediation of maladministration. A proactive approach would better serve the right to administrative justice ${ }^{109} \mathrm{~A}$ procurement system with proactive cognisance of the requirements of lawfulness, reasonableness and procedural fairness in the system would promote the validity of administrative decisions in its execution. Although the flexibility afforded in administrative decision-making may lawfully salvage the proceedings of weak and imperfect transactional systems, such proceedings will be tainted by a departure from the system. The inescapable conclusion is that the solution lies in executing transactional systems that are not only compliant, but that contain provisions enabling certainty in execution. The regulatory system is the means to compel the construction of such systems and in taking full

109 Farina 2004 SAPL 507. The objective should be to promote the validity of administrative action rather than "struggling to prevent its invalidity". 
advantage of all opportunities to strengthen the compliancy of the system before finalisation. By way of conclusion, opportunities for system-process harmonisation were identified during this brief investigation are summarised in the following paragraphs.

Recurrent judicial exposure of system weakness centring on any particular rule will invite future challenge, especially if the outcome is not predictable or deterministic. Prompt response in the development of the regulatory system is necessary to avoid further weaknesses in transactional systems. The regulatory system should certainly not weaken transactional systems by prescribing broad discretion in execution.

The proportionality of filtering rules should be considered prior to publishing. The National Treasury's initiative for central registration with prequalificationary checking should be applauded as it obviates the need for formal filtering rules in transactional systems. ${ }^{110}$ In the event of a bidder error, the possibility of the system's permitting rectification could also be considered.

While a public procurer will be required to formulate specific rules in a transactional system with incomplete knowledge, the invitation to receive representations should be fully utilised before closing, to address system non-compliances. A duty imposed on bidders to make representations regarding flaws in the system prior to closing may have the potential to limit later challenges on such grounds.

There is no doubt that unnecessary challenges to procurement procedures limit the effectiveness of state procurement. A principles-based approach to harmonising the system-centric and process-centric legal requirements in the regulatory system may offer ways to improve compliance through deterministic proceedings.

110 National Treasury $2016 \mathrm{http}: / /$ bit.ly/2FAaUGe. The instruction note prescribes the mandatory use of a central supplier database. 


\section{Bibliography}

\section{Literature}

Arrowsmith, Linarelli and Wallace Regulating Public Procurement Arrowsmith S, Linarelli $\mathrm{J}$ and Wallace $\mathrm{D}$ Regulating Public Procurement, National and International Perspectives (Kluwer Law International The Hague 2000)

Bolton 2009 PELJ

Bolton P "The Committee System for Competitive Bids in Local Government" 2009 PELJ 57-96

Bolton Law of Government Procurement

Bolton P Law of Government Procurement in South Africa (LexisNexis Butterworths Durban 2007)

Carpineti, Piga and Zanza "Variety of Procurement Practice" Carpineti L, Piga G and Zanza M "The Variety of Procurement Practice: Evidence from Public Procurement" in Dimitri N, Piga G and Spagnolo G (eds) Handbook of Procurement (Cambridge University Press New York 2006) $14-47$

Chen 2008 JOPP

Chen T "An Economic Approach to Public Procurement" 2008 JOPP 407430

Christie Law of Contract

Christie R The Law of Contract in South Africa $5^{\text {th }}$ ed (LexisNexis Butterworths Durban 2006)

Csáki "Investigating the Decision Making Practice" Csáki C "Investigating the Decision Making Practice of Public Procurement Procedures" in International Public Procurement Conference Proceedings (September 2006) 869-899

Csáki and Adam 2010 Journal of Decision Systems Csáki C and Adam F "DSS Requirements to Support the Regulated Decision Making Process of Public Procurement" 2010 Journal of Decision Systems 439-464 
De Boer et al "Analysis of Some Mistakes"

De Boer $\mathrm{L}$ et al "An Analysis of Some Mistakes, Miracles and Myths in Supplier Selection" Unpublished contribution delivered at the $15^{\text {th }}$ IPSERA Annual Conference (6-8 April 2006, San Diego, USA)

De Boer, Labro and Morlacci 2001 EJPSM

De Boer L, Labro E and Morlacci P "A Review of Methods Supporting Supplier Selection" 2001 EJPSM 75-89

De la Harpe Public Procurement Law

De la Harpe S Public Procurement Law: A Comparative Analysis (LLDthesis University of South Africa 2009)

De la Harpe "Substantive and Objective Criteria in Preferential Public Procurement"

De la Harpe S "Substantive and Objective Criteria in Preferential Public Procurement: The Case of the 2011 Regulations in South Africa" in Nyeck N (ed) Public Procurement Reform and Governance in Africa (Springer Nature New York 2016) 97-129

Dekel 2008 PCLJ

Dekel $O$ "The Legal Theory of Competitive Bidding for Government Contracts" 2008 PCLJ 237-268

Dekel and Schurr $2014 \operatorname{Rev} L$ \& Econ

Dekel $O$ and Schurr "A Cognitive Biases in Government Procurement - An Experimental Study" 2014 Rev L \& Econ 169-200

Farina 2004 SAPL

Farina C "Administrative Law as Regulation: The Paradox of Attempting to Control and to Inspire the Use of Public Power" 2004 SAPL 489-512

Hoexter Administrative Law

Hoexter C Administrative Law in South Africa (Juta Claremont 2007)

McAfee and McMillan $1987 \mathrm{~J}$ Econ Lit

McAfee R and McMillan J "Auctions and Bidding" 1987 J Econ Lit 699-738

Penfold and Reyburn "Public Procurement"

Penfold G and Reyburn P "Public Procurement" in Chaskalson M et al (eds) Constitutional Law of South Africa Volume $12^{\text {nd }}$ ed (Juta Cape Town 2003) $25-\mathrm{i}-25-36$ 
Quinot 2010 Annu Surv SA L

Quinot G "Administrative Law" 2010 Annu Surv SA L 41-76

Quinot "Promotion of Social Policy"

Quinot G "Promotion of Social Policy through Public Procurement in Africa" in Quinot G and Arrowsmith S (eds) Public Procurement Regulation in Africa (Cambridge University Press Cambridge 2013) 370-403

Sanchez-Graells "Exclusion, Qualitative Selection and Short-listing" Sanchez-Graells A "Exclusion, Qualitative Selection and Short-listing in the New Public Sector Procurement Directive 2014/24" in Lichere F, Caranta R and Treumer S (eds) Modernising Public Procurement: The New Directive (DJØF Publishing Copenhagen 2014) 97-129

Sewpersadh and Mubangizi 2017 PELJ

Sewpersadh $P$ and Mubangizi $J$ "Using the Law to Combat Public Procurement Corruption in South Africa: Lessons from Hong Kong" 2017 PELJ 1-31

Soman "Framing, Loss Aversion and Mental Accounting"

Soman D "Framing, Loss Aversion and Mental Accounting" in Koehler D and Harvey $\mathrm{N}$ (eds) Blackwell Handbook of Judgement and Decision Making (Blackwell Malden 2004) 377-423

Stilger Formulas

Stilger P Formulas for Choosing the Most Economically Advantageous Tender: A Comparative Study (MSc-thesis University of Utrecht 2011)

Trepte Regulating Procurement

Trepte P Procurement Regulation (Oxford University Press Oxford 2006)

Volmink 2014 APPLJ

Volmink $P$ "Legal Consequences of Non-compliance with Bid Requirements" 2014 APPLJ 41-59

Wickens Meaning and Application of Cost-effectiveness

Wickens D The Meaning and Application of Cost-effectiveness as a Constitutional Requirement for the South African Procurement System (LLD-thesis North-West University 2017)

\section{Case law}

Allpay Consolidated Investment Holdings (Pty) Ltd v Chief Executive Officer of the South African Social Security Agency 20141 SA 604 (CC) 
Aurecon South Africa (Pty) Ltd v City of Cape Town 2015 ZASCA 209 (9 December 2015)

Chief Executive Officer, SA Social Security Agency $v$ Cash Paymaster Services (Pty) Ltd 20132 All SA 501 (SCA)

Down Touch Investments $v$ Matjhabeng Local Municipality 2016 ZAFSHC 186 (28 October 2016)

Envitech Solutions (Pty) Limited v Saldanha Bay Municipality 2015 ZAWCHC 108 (13 August 2015)

Grinaker LTA Ltd v The Tender Board (Mpumalanga) 20023 All SA 336 (T) IMVUSA Trading $134 C C$ v Dr. Ruth Mompati District Municipality 2008 ZANWHC 46 (20 November 2008)

Logbro Properties CC v Bedderson 20032 SA 460 (SCA)

Loliwe CC t/a Vusumzi Environmental Services v City of Cape Town 2012 ZAWCHC 162 (6 July 2012)

Menzies Aviation South Africa (Pty) Ltd v SAA (Pty) Ltd 2010 JOL 24726 (GSJ)

Millennium Waste Management v Chairperson Tender Board 20082 SA 481 (SCA)

Minister of Social Development v Phoenix Cash \& Carry Pmb CC 20079 BCLR 982 (SCA)

Premier of the Free State Provincial Government $v$ Firechem Free State (Pty) Ltd 20004 SA 413 (SCA)

Rainbow Civils CC v Minister of Transport and Public Works, Western Cape 2013 ZAWCHC 3 (WCC)

Sanyathi Civil Engineering \& Construction (Pty) Ltd $v$ eThekwini Municipality, Group Five Construction (Pty) Ltd $v$ eThekwini Municipality 20121 All SA 200 (KZP)

Simunye Developers CC v Lovedale Public FET College 2010 ZAECGHC 121 (ECG) 
Sizabonke Civils CC t/a Pilcon Projects v Zululand District Municipality 2010 JOL 25535 (KZP)

South African Post Office Ltd $v$ Chairperson of Western Cape Provincial Tender Board 20015 BCLR 500 (C)

Steenkamp v Provincial Tender Board of the Eastern Cape 2007 3 SA 121 (CC)

Transnet Limited v Goodman Brothers (Pty) Ltd 20012 BCLR 176 (SCA)

Trencon Construction (Pty) Limited $v$ Industrial Development Corporation of South Africa Limited 20155 SA 245 (CC)

Umfolozi Transport (Edms) Bpk v Minister van Vervoer 19972 All SA 548 (A)

Viking Pony Africa Pumps (Pty) Ltd t/a Tricom Africa v Hidro-Tech Systems (Pty) Ltd 20112 BCLR 207 (CC)

Westinghouse Electric Belgium Societe Anonyme v Eskom Holdings (Soc) Ltd 20161 All SA 483 (SCA)

\section{Legislation}

Broad-based Black Economic Empowerment Act 53 of 2003

Constitution of the Republic of South Africa, 1996

Electricity Regulation Act 4 of 2006

Local Government: Municipal Finance Management Act 56 of 2003

Preferential Procurement Policy Framework Act 5 of 2000

Promotion of Administrative Justice Act 3 of 2000

Public Finance Management Act 1 of 1999

\section{Government publications}

GN R225 in GG 27388 of 15 March 2005

GN R502 in GG 34350 of 8 June 2011

GN R32 in GG 40553 of 20 January 2017 
Public Contracts Regulations 2015, SI 2015/102 (UK)

\section{Internet sources}

Consumer Unity and Trust Society International Date Unknown http://www.cuts-international.org/pdf/Executive\%20Summary.pdf

CUTS International Date Unknown Executive Summary http://www.cutsinternational.org/pdf/Executive\%20Summary.pdf accessed 8 February 2018

Lexico $2021 \mathrm{https}$ ://www.lexico.com/definition/process

Lexico 2021 Process https://www.lexico.com/definition/process accessed 8 February 2017

Lexico $2021 \mathrm{https}: / /$ www.lexico.com/definition/system

Lexico 2021 System https://www.lexico.com/definition/system accessed 8 February 2017

National Treasury 2016 http://bit.ly/2FAaUGe

National Treasury 2016 SCM Instruction No 4A of 2016/2017: Central Supplier Database http://bit.ly/2FAaUGe accessed 8 February 2018

\section{List of Abbreviations}

PFMA

PFMAR

PPPFA

Rev L \& Econ

SAPL

Annu Surv SA L

APPLJ

CUTS

EJPSM

JOPP

J Econ Lit

PAJA

PCLJ

PELJ
Public Finance Management Act 1 of 1999

Regulations to the Public Finance Management Act 1 of 1999

Preferential Procurement Policy Framework Act 5 of 2000

Review of Law and Economics

Southern African Public Law

Annual Survey of South African Law

African Public Procurement Law Journal

Consumer Unity and Trust Society

European Journal of Purchasing and Supply Management

Journal of Public Procurement

Journal of Economic Literature

Promotion of Administrative Justice Act 3 of 2000

Public Contract Law Journal

Potchefstroom Electronic Law Journal 